\title{
Improved Gettering Efficiency of Ni from Nickel-Mediated Crystallization Silicon Using Phosphorus-Doped Amorphous Silicon
}

\author{
BAU-MING WANG ${ }^{1}$ and YEWCHUNG SERMON WU ${ }^{1,2}$ \\ 1.-Department of Materials Science and Engineering, National Chiao Tung University, 1001 \\ Ta-Hsueh Road, Hsinchu 300, Taiwan, ROC. 2.—e-mail: SermonWu@StanfordAlumni.org \\ Ni-metal-induced lateral crystallization (NILC) has been utilized to fabricate \\ polycrystalline silicon thin-film transistors. However, the NILC process often \\ leads to $\mathrm{Ni}$ and $\mathrm{NiSi}_{2}$ precipitates being trapped. In this study, two kinds of \\ films were used as gettering layers: (1) amorphous Si and (2) phosphorus- \\ doped amorphous Si. After annealing at $550^{\circ} \mathrm{C}$ for $12 \mathrm{~h}$, it was found that \\ phosphorous dopant did improve the gettering efficiency of amorphous $\mathrm{Si}$.
}

Key words: $\mathrm{Ni}$ gettering, phosphorus dopant, chemical oxide (chem- $\mathrm{SiO}_{2}$ )

\section{INTRODUCTION}

Low-temperature polycrystalline silicon (LTPS) thin-film transistors (TFTs) have attracted considerable interest for their use in active-matrix liquidcrystal displays (AMLCDs) because they exhibit good electrical properties and can be integrated in peripheral circuits on inexpensive glass substrates. ${ }^{1}$ Since polycrystalline silicon (poly-Si) TFTs require glass substrates, intensive studies have been carried out to lower the crystallization temperature of amorphous silicon $(\alpha-\mathrm{Si})$ films. Ni-metal-induced lateral crystallization (NILC) is one of these efforts. In NILC, Ni islands on the top of $\alpha-\mathrm{Si}$ films are allowed to crystallize at a temperature below $600^{\circ} \mathrm{C}$. The poly-Si formed under the $\mathrm{Ni}$ islands is called Ni-metal-induced crystallization (NIC), whereas the poly-Si formed outside the metal layer is called NILC. Unfortunately, the NILC poly-Si grain boundaries trap $\mathrm{Ni}$ and $\mathrm{NiSi}_{2}$ precipitates, which increase the leakage current and shift the threshold voltage. ${ }^{2-6}$ Therefore, Ni contamination inside the NILC poly-Si film should be reduced. Several metal gettering methods have been employed to reduce the amount of undesired metallic impurities in $\mathrm{Si}^{7-11}$ These gettering methods are complicated and require high process temperatures.

(Received October 27, 2008; accepted March 2, 2009;

published online March 28, 2009)
In previous studies, we have proposed several methods for reducing $\mathrm{Ni}$ concentration inside the NILC film. They involve using $\alpha$-Si/silicon-nitride films, $\alpha$-Si-coated Si wafer, and contact holes covered with $\alpha$-Si film. ${ }^{12-14}$ During the gettering process, $\mathrm{Ni}$ atoms were diffused from the NILC film to the $\alpha$-Si layer due to the concentration gradient. However, when the system reached equilibrium, no more $\mathrm{Ni}$ diffused into the gettering layer. At this point, the Ni concentration in the $\alpha$-Si layer was the same as that in NILC. In this study, phosphorus-doped $\alpha-\mathrm{Si}(\mathrm{P}-\alpha-\mathrm{Si})$ film and chemical $\mathrm{SiO}_{2}$ (chem-SiO $\mathrm{S}_{2}$ ) layer were used as gettering layers. The effect of phosphorus dopant on the Ni-gettering efficiency was investigated.

\section{EXPERIMENTAL}

Three kinds of poly-Si films were investigated in this study. One was a poly-Si film fabricated by traditional NILC method without the gettering process (referred to as NoGET), and the others were poly-Si films fabricated by the same NILC method with different $\mathrm{Ni}$-gettering layers (referred to as ASiGET and PSiGET). The NILC fabrication process began with capping 4 -inch $\mathrm{Si}(100)$ wafers with 500 -nm-thick wet thermal oxide. Then, silane-based 100 -nm-thick $\alpha$-Si films were deposited using lowpressure chemical vapor deposition (LPCVD) at $550^{\circ} \mathrm{C}$ in $\mathrm{N}_{2}$ ambient. The photoresist was patterned to form desired $\mathrm{Ni}$ lines, and a 5-nm-thick Ni film was deposited on the $\alpha$-Si. 
(a)

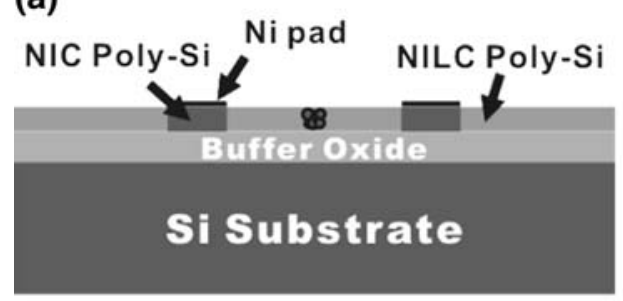

(c)

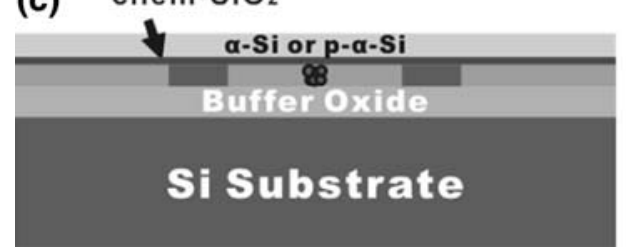

(b)

NILC/NILC Boundary

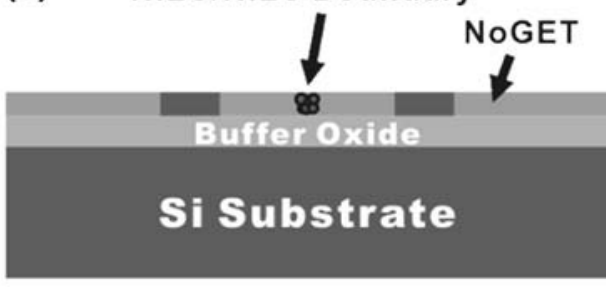

(d)

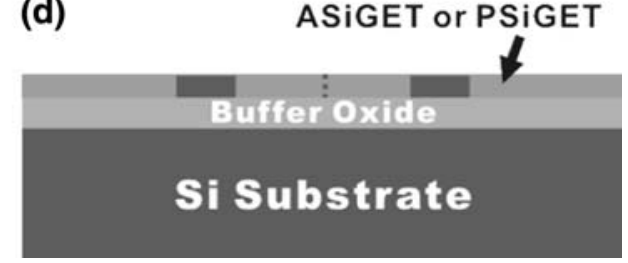

Fig. 1. Schematic illustration of the Ni-gettering process: (a) fabrication of NILC poly-Si, (b) removal of unreacted Ni, (c) capped with a chem$\mathrm{SiO}_{2}$ layer and a gettering layer $(\alpha-\mathrm{Si}$ or $\mathrm{P}-\alpha-\mathrm{Si})$, and (d) removal of the gettering layer and chem-SiO ${ }_{2}$ layer.

To form NoGET poly-Si films, samples were annealed at $540^{\circ} \mathrm{C}$ for $24 \mathrm{~h}$ in $\mathrm{N}_{2}$, as shown in Fig. 1a. The unreacted $\mathrm{Ni}$ was then removed by a mixed solution of $\mathrm{H}_{2} \mathrm{SO}_{4}$ and $\mathrm{H}_{2} \mathrm{O}_{2}$ for $20 \mathrm{~min}$. Finally, poly-Si films were dipped into $1 \%$ diluted hydrogen fluoride (DHF) solution to remove the annealing surface oxide, as illustrated in Fig. $1 b$.

As for the ASiGET poly-Si film, a NoGET poly-Si film was dipped into a mixed solution of $\mathrm{H}_{2} \mathrm{SO}_{4}$ and $\mathrm{H}_{2} \mathrm{O}_{2}$ for 10 min to form a chem-SiO ${ }_{2}$ layer on the top of NILC poly-Si. A $100-n m$-thick $\alpha$-Si film was then deposited on the chem- $\mathrm{SiO}_{2}$ layer using LPCVD at $550^{\circ} \mathrm{C}$ for $1 \mathrm{~h}$ in $\mathrm{N}_{2}$ ambient, as shown in Fig. 1c. The top $\alpha$-Si film served as the Ni-gettering layer. To examine the quality of chem-SiO ${ }_{2}$, after the chem- $\mathrm{SiO}_{2}$ layer was formed, platinum was deposited on top of the chem- $\mathrm{SiO}_{2}$ for image contrast in transmission electron microscopy (TEM) sample preparation. As shown in Fig. 2, the oxide layer was only about $5 \mathrm{~nm}$ thick. This chemical oxide layer was used as an etching stop layer in the 5\% tetramethylammonium hydroxide (TMAH) etching solution. Moreover, this thin oxide layer also served as a diffusion interlayer during the Ni-gettering process. $\mathrm{Ni}$ atoms needed to diffuse from the NILC-Si through the thin chem- $\mathrm{SiO}_{2}$ into the Ni-gettering layer.

As for the PSiGET poly-Si film, phosphorous ions were implanted into $\alpha$-Si to form a P- $\alpha-S i$ film, as shown in Fig. 1c. The projection range of ions was set at the middle of the $\alpha$-Si film. The dosage of phosphorous ions and the ion-accelerating energy were $1 \times 10^{16} \mathrm{~cm}^{-2}$ and $35 \mathrm{keV}$, respectively.

Samples undergoing Ni-gettering were then annealed at $550^{\circ} \mathrm{C}$ for $12 \mathrm{~h}$ in $\mathrm{N}_{2}$ ambient with the goal of removing the unwanted $\mathrm{Ni}$ metal inside the NILC-Si. Following the annealing process, the top Ni-gettering films were removed using 5\% TMAH for $2 \mathrm{~min}$ at $55^{\circ} \mathrm{C}$, and the chem- $\mathrm{SiO}_{2}$ layers were

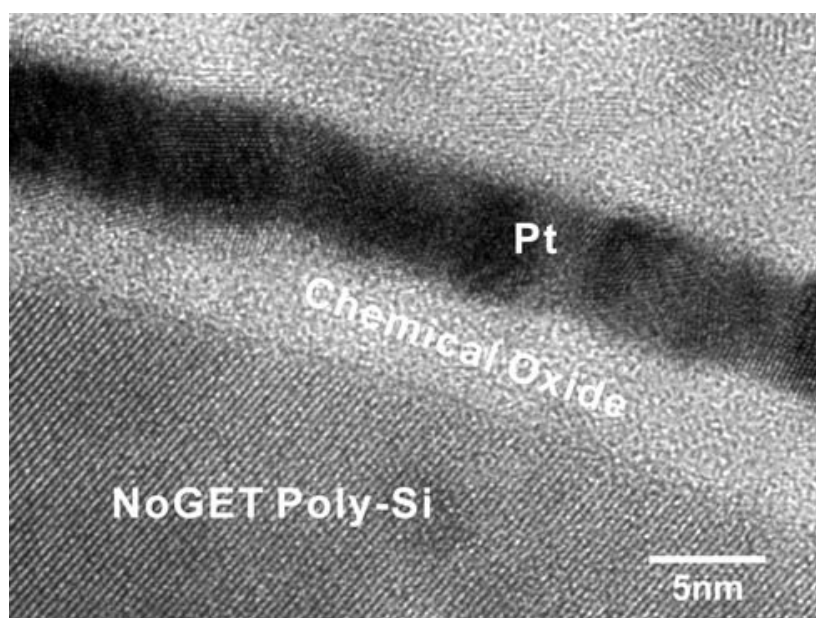

Fig. 2. TEM image of the cross-section of the NoGET film caped with $\sim 5$-nm-thick chem-SiO ${ }_{2}$ layer. Platinum film deposited on the top of the chem-SiO 2 layer was for TEM sample preparation.

removed using 1\% DHF solution, as shown in Fig. 1d. To study the effect of gettering on the surface roughness of NILC poly-Si, the NILC surfaces were measured using atomic force microscopy (AFM). It was found that the metal gettering did not change the surface roughness greatly: the rootmean-square $(\mathrm{rms})$ roughness of ASiGET $(0.65 \mathrm{~nm})$ and PSiGET $(0.69 \mathrm{~nm})$ were almost the same as that of NoGET $(0.64 \mathrm{~nm})$.

For the purpose of comparison, the NoGET polySi film was also subjected to an extended heat treatment at $550^{\circ} \mathrm{C}$ for $12 \mathrm{~h}$ in $\mathrm{N}_{2}$ ambient.

\section{RESULTS AND DISCUSSION}

The NoGET film was composed of NILC poly-Si grains. ${ }^{12}$ After the formation of gettering layers and the gettering process, the Ni-gettering layers 

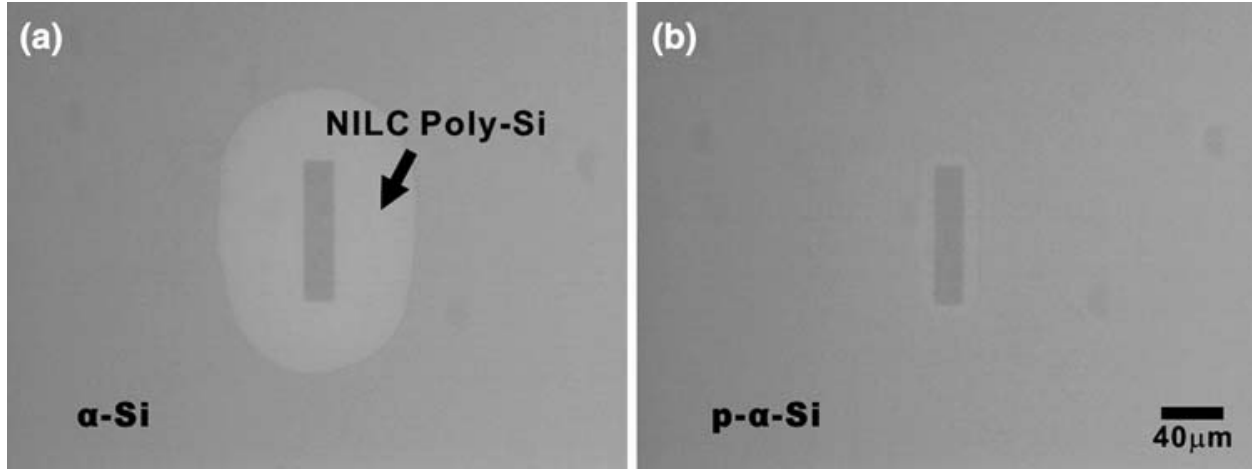

Fig. 3. OM images of gettering layers after annealing at $550^{\circ} \mathrm{C}$ for $12 \mathrm{~h}$ : (a) $\alpha$-Si and (b) p- $\alpha$-Si.

$(\alpha-\mathrm{Si}$ and $\mathrm{P}-\alpha-\mathrm{Si})$ were examined by optical microscopy $(\mathrm{OM})$ to investigate the gettering efficiency. The results are shown in Fig. 3. In the figure, the pink region was $\alpha$-Si and the green region was needle-like NILC poly-Si, which has been verified using scanning electron microscopy (SEM) and TEM. ${ }^{12}$ The pale-green region in Fig. $3 \mathrm{~b}$ was NILC poly-Si on NoGET film underneath the chem- $\mathrm{SiO}_{2}$ layer. This means that, during the gettering process, $\mathrm{Ni}$ atoms diffused from the NoGET film through chem-SiO $\mathrm{S}_{2}$ into the Ni-gettering layer due to the concentration gradient. When $\mathrm{Ni}$ atoms reached the gettering film, enough $\mathrm{Ni}$ metal would be accumulated to form $\mathrm{NiSi}_{2}$ precipitates, and $\alpha-\mathrm{Si}$ would then be transformed into needle-like polySi grains by the NILC mechanism. NILC poly-Si grains first appeared right above the top of the NIC area, and then extended to the surrounding areas. This is because the $\mathrm{Ni}$ concentration above the NIC area was higher than that in other areas of the gettering film. Therefore, we can still see the NIC strip patterns.

Figure 3 also shows that the length of the NILC poly-Si growth on the $\mathrm{P}-\alpha-\mathrm{Si}$ gettering layer was $13 \mu \mathrm{m}$, which was much shorter than that $(60 \mu \mathrm{m})$ on the $\alpha$-Si gettering layer. Since the NILC grains were induced by indiffusion of $\mathrm{Ni}$ atoms, it seemed that phosphorous dopant did not improve the gettering efficiency of $\alpha$-Si.

In addition to the gettering layer, the gettering efficiencies of ASiGET and PSiGET poly-Si films were also investigated. After the gettering layer and chem- $\mathrm{SiO}_{2}$ were removed, the samples were dipped into a silicide-etching solution $\left(\mathrm{HNO}_{3}: \mathrm{NH}_{4} \mathrm{~F}: \mathrm{H}_{2} \mathrm{O}=\right.$ 4:1:50). As shown in Fig. 4a and b, numerous holes were observed at the boundaries where two NILC poly-Si fronts intersected (NILC/NILC boundaries). These holes were residues of the Ni silicide that had been etched away by the silicide-etching solution. These silicide-etching holes seen in Fig. $4 \mathrm{~b}$ were quite sensitive to the reduction of $\mathrm{Ni}$ residue in the NILC poly-Si, and were therefore ideal for elucidating the "Ni gettering" phenomenon observed. After the gettering process, fewer and smaller (a)

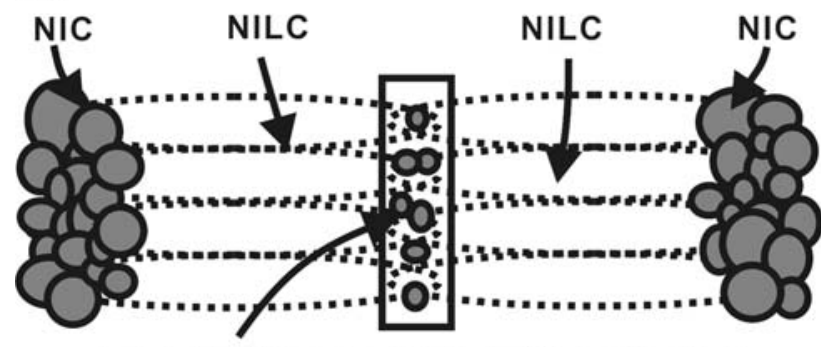

two poly-Si front collided with each other (b)

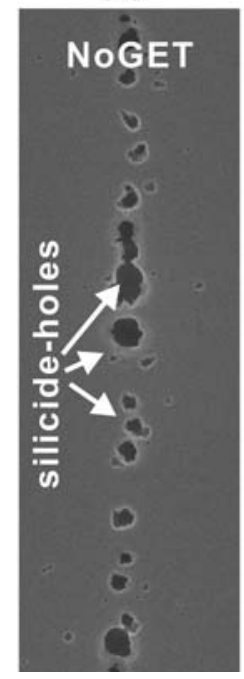

(c)

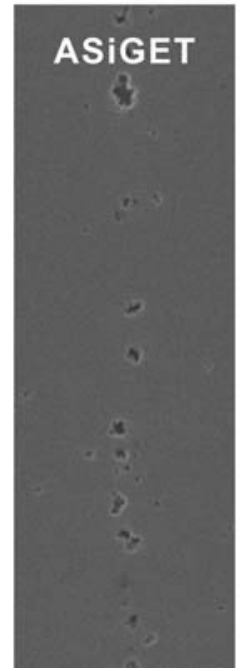

(d)

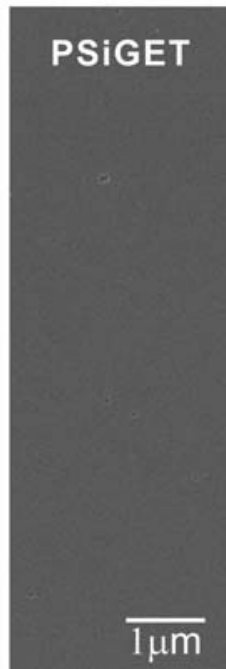

Fig. 4. Schematic illustration of (a) silicide-etching holes at NILC/ NILC boundaries, and SEM images of etching holes of (b) NoGET, (c) ASiGET, and (d) PSiGET.

silicide-etching holes were found at the NILC/NILC boundaries of ASiGET, as shown in Fig. 4c. Furthermore, there were almost no silicide-etching holes observed at the NILC/NILC boundaries of PSiGET, as shown in Fig. 4d. These results indicate that phosphorous dopant did improve the gettering efficiency of $\alpha-\mathrm{Si}$, which was different from our OM observation of gettering layers (Fig. 3). 

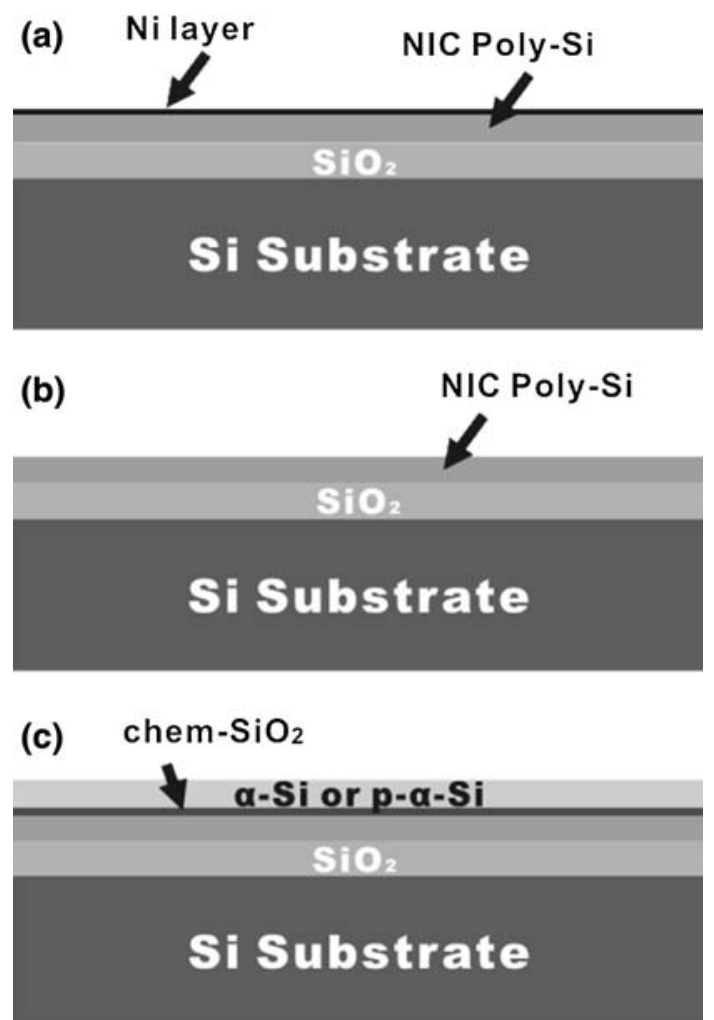

Fig. 5. Schematic illustration of the gettering process of the NIC poly-Si: (a) fabrication of the NIC poly-Si, (b) removal of unreacted $\mathrm{Ni}$, and (c) capped with a chem- $\mathrm{SiO}_{2}$ layer and a gettering layer $(\alpha-\mathrm{Si}$ or $\mathrm{P}-\alpha-\mathrm{Si})$.

Secondary-ion mass spectroscopy (SIMS) was employed to clarify the Ni concentration in PSiGET and ASiGET. Unfortunately, the Ni concentration in the NILC poly-Si is hard to measure since the SIMS sputtering area $\left(125 \mu \mathrm{m} \times 125 \mu \mathrm{m}^{2}\right)$ is much larger than that in the NILC poly-Si area. Therefore, we used NIC poly-Si to demonstrate that phosphorus dopant did improve the gettering efficiency of $\alpha$-Si. The fabrication process of NIC poly-Si is shown in Fig. 5. Silane-based 100-nm-thick $\alpha$-Si films were deposited using LPCVD at $550^{\circ} \mathrm{C}$ in $\mathrm{N}_{2}$ ambient, as shown in Fig. 5a. A 5-nm-thick Ni film was then deposited on the $\alpha-\mathrm{Si}$, and subsequently annealed at $540^{\circ} \mathrm{C}$ for $24 \mathrm{~h}$ to form NIC poly-Si. The unreacted $\mathrm{Ni}$ was then removed by a mixed solution of $\mathrm{H}_{2} \mathrm{SO}_{4}$ and $\mathrm{H}_{2} \mathrm{O}_{2}$ for 20 min, as shown in Fig. 5b. The poly-Si film was dipped into a mixed solution of $\mathrm{H}_{2} \mathrm{SO}_{4}$ and $\mathrm{H}_{2} \mathrm{O}_{2}$ to form a chem-SiO 2 layer. A 100$\mathrm{nm}$-thick $\alpha$-Si film was then deposited on the chem$\mathrm{SiO}_{2}$ layer using LPCVD at $550^{\circ} \mathrm{C}$ for $1 \mathrm{~h}$ in $\mathrm{N}_{2}$ ambient to form the $\alpha$-Si gettering layer, as shown in Fig. 5c. Phosphorous ions were implanted into $\alpha$-Si to form the P- $\alpha$-Si gettering layer. Samples were then annealed at $550^{\circ} \mathrm{C}$ for $12 \mathrm{~h}$ in $\mathrm{N}_{2}$ ambient.

Even though the Ni concentration in NIC poly-Si was much higher than that in NILC poly-Si, we can still have a preliminary understanding of the gettering efficiency of $\alpha$-Si films. Figure 6 shows that

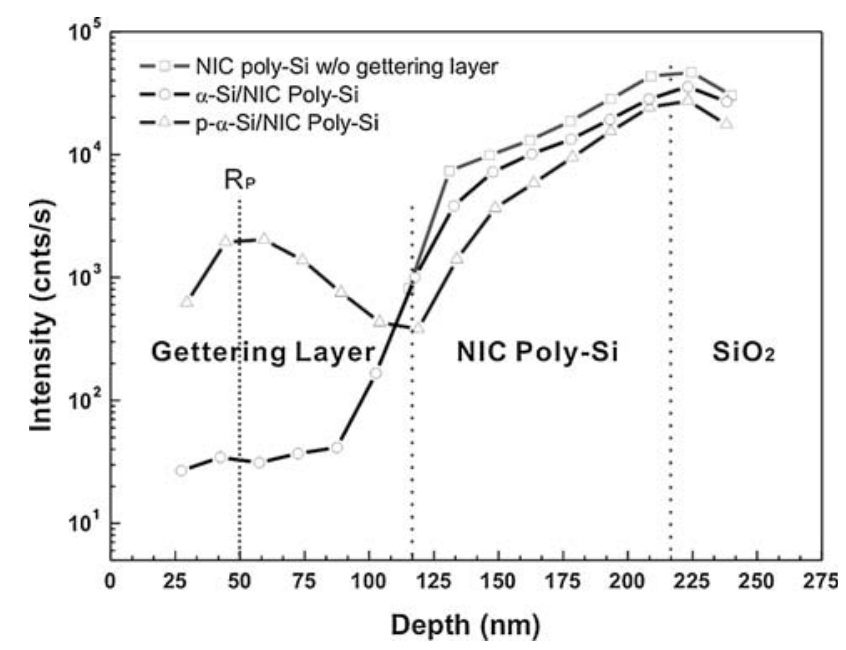

Fig. 6. SIMS depth profiles of the NIC poly-Si films. $R_{\mathrm{P}}$ is the projection range of phosphorous ions.

the Ni concentration of NIC poly-Si was reduced after the Ni-gettering process. As can be seen, the $\mathrm{Ni}$ concentration in NIC poly-Si with the $\alpha-\mathrm{Si}$ gettering layer was relatively higher than that with the $\mathrm{P}-\alpha-\mathrm{Si}$ gettering layer. Moreover, $\mathrm{P}-\alpha-\mathrm{Si}$ traps many more $\mathrm{Ni}$ atoms than does $\alpha$-Si in the gettering layer. These results indicate that phosphorous dopant did improve the gettering efficiency of $\alpha$-Si. Phosphorus implant and implant damage trap $\mathrm{Ni}$ and slow down the NILC rate on the gettering layer. ${ }^{15}$ As a result, the length of the NILC poly-Si growth on P- $\alpha-\mathrm{Si}$ (Fig. 3) was much shorter than that on $\alpha$-Si, but the silicide-etching holes (Fig. 4) of PSiGET were fewer and smaller than those of ASiGET.

Figure 6 also shows that the middle of the $\mathrm{P}-\alpha-\mathrm{Si}$ layer had a higher $\mathrm{Ni}$ concentration than other parts of the layer. This concentration distribution of $\mathrm{Ni}$ was similar to that of phosphorous atoms since the projection range of phosphorous ions was set at the middle of the $\alpha$-Si film. This result also indicates that phosphorus did trap Ni atoms.

In the gettering process, when more $\mathrm{Ni}$ atoms diffused into the gettering layer, more $\alpha$-Si would be transformed into poly-Si by the NILC mechanism. The gettering efficiency increased with the growth of NILC poly-Si grains. However, when the system reached equilibrium, no more $\mathrm{Ni}$ could diffuse into the gettering layer. At this point, the $\mathrm{Ni}$ concentration in the $\alpha$-Si gettering layer will be the same as that in ASiGET. However, the Ni concentration in the $\mathrm{P}-\alpha$-Si gettering layer will be higher than that in PSiGET since phosphorus implant traps $\mathrm{Ni}$ atoms. In other words, the gettering efficiency of $\alpha-\mathrm{Si}$ is indeed improved by phosphorous dopant.

\section{CONCLUSION}

Two kinds of films were employed to investigate the effect of phosphorus dopant on the gettering efficiency of $\alpha$-Si. To form the ASiGET and PSiGET, 
a $\sim 5$-nm-thick porous chem- $\mathrm{SiO}_{2}$ layer was capped on the top of the NoGET film, and then either a $\alpha-\mathrm{Si}$ or a P- $\alpha-\mathrm{Si}$ film was deposited on the top of the chem-SiO ${ }_{2}$ film. The chem-SiO ${ }_{2}$ layer was used as an etching stop layer, while the Si film served as a gettering layer. It was found that the $\mathrm{Ni}$ concentration in the NoGET film was greatly reduced after gettering at $550^{\circ} \mathrm{C}$ for $12 \mathrm{~h}$. Compared with those on the NoGET film, the silicide-etching holes found at the NILC/NILC boundaries of ASiGET were fewer and smaller, while almost no holes were observed at the boundaries of PSiGET. This is because the concentration gradient acts as a driving force for transport of Ni from the NoGET poly-Si through the chem-SiO $\mathrm{S}_{2}$ layer to the gettering layer.

It was also found that the gettering layer was transformed into poly-Si by the NILC mechanism. The NILC fraction in the gettering layer increased with an increase in annealing time and temperature, as expected from the kinetic nature of the diffusion process. Moreover, the length of NILC poly-Si growth on the $\mathrm{P}-\alpha-\mathrm{Si}$ gettering layer was much shorter than that on the $\alpha$-Si gettering layer. This is because phosphorus implant and implant damage trap Ni and slow down the NILC rate on the gettering layer. In other words, the gettering efficiency of $\alpha-\mathrm{Si}$ is indeed improved by the doping of phosphorous.

\section{ACKNOWLEDGEMENTS}

This project was funded by Sino American Silicon Products Incorporation and the National Science Council of the Republic of China under Grant No. 95-2221-E009-087-MY3. Technical support from the
National Nano Device Laboratory, Center for Nano Science and Technology, and the Nano Facility Center of the National Chiao Tung University are also acknowledged.

\section{REFERENCES}

1. M. Stewart, R.S. Howell, L. Pires, and M.K. Hatalis, IEEE Trans. Electron. Dev. 48, 845 (2001). doi:10.1109/16.918227.

2. P.J. van der Zaag, M.A. Verheijen, S.Y. Yoon, and N.D. Young, Appl. Phys. Lett. 81, 3404 (2002). doi:10.1063/1.151 7406.

3. G.A. Bhat, Z. Jin, H.S. Kwok, and M. Wong, IEEE Electron. Dev. Lett. 20, 97 (1999). doi:10.1109/55.740664.

4. Z. Jin, K. Moulding, H.S. Kowk, and M. Wong, IEEE Electron. Dev. Lett. 20, 167 (1999). doi:10.1109/55.753755.

5. G.A. Bhat, H.S. Kwok, and M. Wong, Solid-State Electron. 44, 1321 (2000). doi:10.1016/S0038-1101(99)00328-7.

6. D. Murley, N. Young, M. Trainor, and D. McCulloch, IEEE Trans. Electron. Dev. 48, 1145 (2001). doi:10.1109/16.92 5240.

7. B. Mohadjeri, J.S. Williams, and J.W. Leung, Appl. Phys. Lett. 66, 1889 (1995). doi:10.1063/1.113311.

8. M. Zhang, X. Zeng, P.K. Chu, R. Scholz, and C. Lin, J. Vac. Sci. Technol. A 18, 2249 (2000). doi:10.1116/1.1288138.

9. R. Hoelzl, K.J. Range, L. Fabry, J. Hage, and V. Raineri, Mater. Sci. Eng. B 73, 95 (2000). doi:10.1016/S0921-5107(99) 00442-0.

10. S. Martinuzzi, I. Perichaud, and J.J. Simon, Appl. Phys. Lett. 70, 2744 (1997). doi:10.1063/1.119009.

11. S. Martinuzzi, N.G. Henquinet, I. Périchaud, G. Mathieu, and F. Torregrossa, Mater. Sci. Eng. B 71, 229 (2000). doi: 10.1016/S0921-5107(99)00380-3.

12. C.Y. Hou and Y.S. Wu, Electrochem. Solid-State Lett. 9, H65 (2006). doi:10.1149/1.2203353.

13. C.M. Hu, Y.S. Wu, and C.C. Lin, IEEE Electron. Dev. Lett. 28, 1000 (2007). doi:10.1109/LED.2007.907267.

14. C.M. Hu and Y.S. Wu, Jpn. J. Appl. Phys. 46, L1188 (2007). doi:10.1143/JJAP.46.L1188.

15. T. Ma and M. Wong, J. Appl. Phys. 91, 1236 (2002). doi: 10.1063/1.1430531. 